\title{
Solvent Diffusion in Amorphous Polymers: Polystyrene-Solvent Systems
}

\author{
FUNDA TIHMINLIOGLU, ${ }^{1}$ RONALD P. DANNER ${ }^{2}$ \\ ${ }^{1}$ Chemical Engineering Department, Izmir Institute of Technology, Gaziosmanpasa Bulv. No. 16 35230, Izmir, Turkey \\ ${ }^{2}$ Center for the Study of Polymer-Solvent Systems, Chemical Engineering Department, Pennsylvania State University, \\ University Park, Pennsylvania 16802
}

Received 8 December 1999; revised 9 February 2000; accepted 2 May 2000

\begin{abstract}
The inverse gas chromatography (IGC) technique was used to obtain the partition and diffusion coefficients of solvents in polystyrene over a wide range of temperatures. Infinite dilution experiments were performed with three solvents: toluene, benzene, and hexane. Finite concentration data were measured for the polystyrene-toluene system at various concentrations from 110 to $180{ }^{\circ} \mathrm{C}$. For the finite concentration region, the modified capillary column model used by Tihminlioglu and Danner (J Chromatogr A 1999, 845, 93-101) was used to calculate diffusion and thermodynamic data. Finite concentration thermodynamic data were also calculated with the retention theory approach and compared with the capillary column model. The experimental IGC results are in good agreement with data from other experimental techniques. () 2000 John Wiley \& Sons, Inc. J Polym Sci B: Polym Phys 38: 1965-1974, 2000
\end{abstract}

Keywords: polystyrene; solvent diffusion; inverse gas chromatography; polymer

\section{INTRODUCTION}

In the production of most polymers, residual low molecular weight species, such as monomers or solvents, remain in the product. To meet quality, health, safety, and environmental standards, these low molecular weight species must be removed by devolatilization steps. Information on the diffusivity and solubility of the solvents in the polymer is required to design and optimize devolatilization processes. The inverse gas chromatography (IGC) technique can be used as a tool to accurately measure the solubility and diffusivity in polymer-solvent systems. In recent years, the technique has become increasingly popular for sorption measurements in polymer-solvent systems in the limit of zero solvent concentration. Various researchers ${ }^{1-6}$ have used this technique

Correspondence to: R. P. Danner (E-mail: rpd@psu.edu) Journal of Polymer Science: Part B: Polymer Physics, Vol. 38, 1965-1974 (2000) (ㅇ) 2000 John Wiley \& Sons, Inc. to measure infinitely dilute diffusion and partition coefficients in binary polymer-solvent systems. Their results compare well with those obtained from conventional techniques and are reproducible. The ease of the experimental technique coupled with rapid and accurate results has made IGC an important tool for measuring the solubility and diffusivity in polymer-solvent systems. In the past, however, IGC has been limited to measurements at infinitely dilute conditions. The technique has been extended for thermodynamic measurements to the finite concentration region by a number of researchers. Previously, only Tihminlioglu et al. ${ }^{6}$ have reported measuring diffusion coefficients at finite concentrations with this technique. In this article, the IGC technique has been applied to determine the partition and diffusion coefficients of three polymer-solvent systems: polystyrene (PS)-toluene, PS-benzene, and PS-hexane at infinite dilution of the solvent and in the finite concentration region for the PStoluene system. 


\section{THEORETICAL ANALYSIS}

\section{Capillary Column Model}

The method of analyzing the response from a capillary column inverse gas chromatography (CCIGC) for an infinitely dilute input pulse was presented by Pawlisch et al. ${ }^{2,3}$ and Arnould and Laurence. ${ }^{7}$ Through modeling of the response peak, partition and diffusion coefficients are determined for infinitely dilute systems. For finite concentration studies, the experimental setup used in the infinitely dilute case and the original model developed by Pawlisch need to be modified. These modifications were discussed in detail in an article by Tihminlioglu et al. ${ }^{8}$ With the continuity equations for the gas and polymer phases written with appropriate boundary conditions, the dimensionless equation for the response peak at the exit of the column becomes in the Laplace domain

$$
\begin{aligned}
\frac{C L}{C_{o} u}=\exp \left(\frac{1}{2 \Gamma}\right) \exp [ & -\left(\frac{1}{4 \Gamma^{2}}+\frac{S}{\Gamma}\right. \\
& \left.\left.+\frac{2 \sqrt{S}}{\alpha \beta \Gamma} \tan h(\beta \sqrt{S})\right)^{1 / 2}\right] \\
\Gamma=\frac{D_{g}}{u L} \quad \alpha= & \frac{R}{K(1-\Psi) \tau} \quad \beta^{2}=\frac{\tau^{2}}{D_{p} t_{c}}
\end{aligned}
$$

Here, $\tau$ is the thickness of the polymer film, $K$ is equal to $d C^{\prime} / d C$ (which for the infinitely dilute case is equal to $C^{\prime} / C$, the partition coefficient, $K_{p}$ ), $S$ is the Laplace operator, and $D_{g}$ and $D_{p}$ are the gas-phase and polymer-phase diffusion coefficients, respectively. The elution profile is a function of the three dimensionless parameters, $\alpha, \beta$, and $\Gamma . \alpha$ is inversely related to the partition coefficient, $\beta^{2}$ is similarly related to the polymer diffusion coefficient, and $\Gamma$ varies proportionately with the gas-phase diffusion coefficient. In other words, the parameter $\alpha$ is a thermodynamic parameter, whereas $\beta$ and $\Gamma$ represent the polymerphase and gas-phase transport properties. $\Psi$ is the true mole fraction obtained by correction for the gas-phase nonideality and for compressibility effects due to the pressure gradient in the column. ${ }^{9}$ The concentration in the polymer phase is obtained by integration of the $d C^{\prime} / d C$ values from zero concentration to the concentration of interest. The ratio $C^{\prime} / C$ is then the partition coefficient obtained from the CCIGC model.
In eq 1 , the outlet concentration profile from the gas chromatogram is made dimensionless with the inlet concentration and the carrier-gas retention time. The experimental data are regressed with eq 1 to obtain the partition and diffusion coefficients for the finite concentration of the solvent. A fast Fourier inverse transform is used to invert the solution of the CCIGC model from the Laplace domain to the time domain. A nonlinear regression to minimize the error between the experimental data and model predictions is carried out with the Levenberg-Marquardt algorithm. The first and second moments of the elution profile are used to get initial estimates of $d C^{\prime} / d C$ and $D_{p}$ for the regression. Equation 1 is identical to that derived by Pawlisch et al. $^{2,3}$ and Arnould and Laurence ${ }^{7}$ except for the addition of the $1-\Psi$ term in the $\alpha$ parameter. This term accounts for the change in the velocity with concentration, that is, the sorption effect. ${ }^{10}$ The $\Psi$ parameter is equal to zero at infinite dilution conditions.

\section{Retention Volume Theory}

Theoretical relationships that were developed by Conder and Young ${ }^{9}$ and Price and Guillet ${ }^{10}$ are used to calculate the retention volumes and sorption isotherms. The retention volume, $V_{N}$, is given by the expression

$$
V_{N}=V_{s}(1-\Psi) \frac{d^{\prime} C}{d C}
$$

Here, $V_{N}$ is the net retention volume, and $V_{s}$ is the volume of the stationary phase. Through the integration of eq 3 and the introduction of the weight of polymer used, $W$, the concentration of the solvent in the polymer phase, $Q$, can be found.

Here, $j$ is the pressure-drop correction factor. ${ }^{9}$

$$
Q=\frac{j}{W} \int_{0}^{C} \frac{V_{N}}{(1-\Psi)} d C
$$

To determine an isotherm, retention volumes were measured for a series of solute concentrations. The evaluation of the integral was done by the fitting of a polynomial to the data and then integration.

\section{Free-Volume Theory}

The most successful models for describing the diffusion of low molecular weight penetrants or 
Thermal conductivity

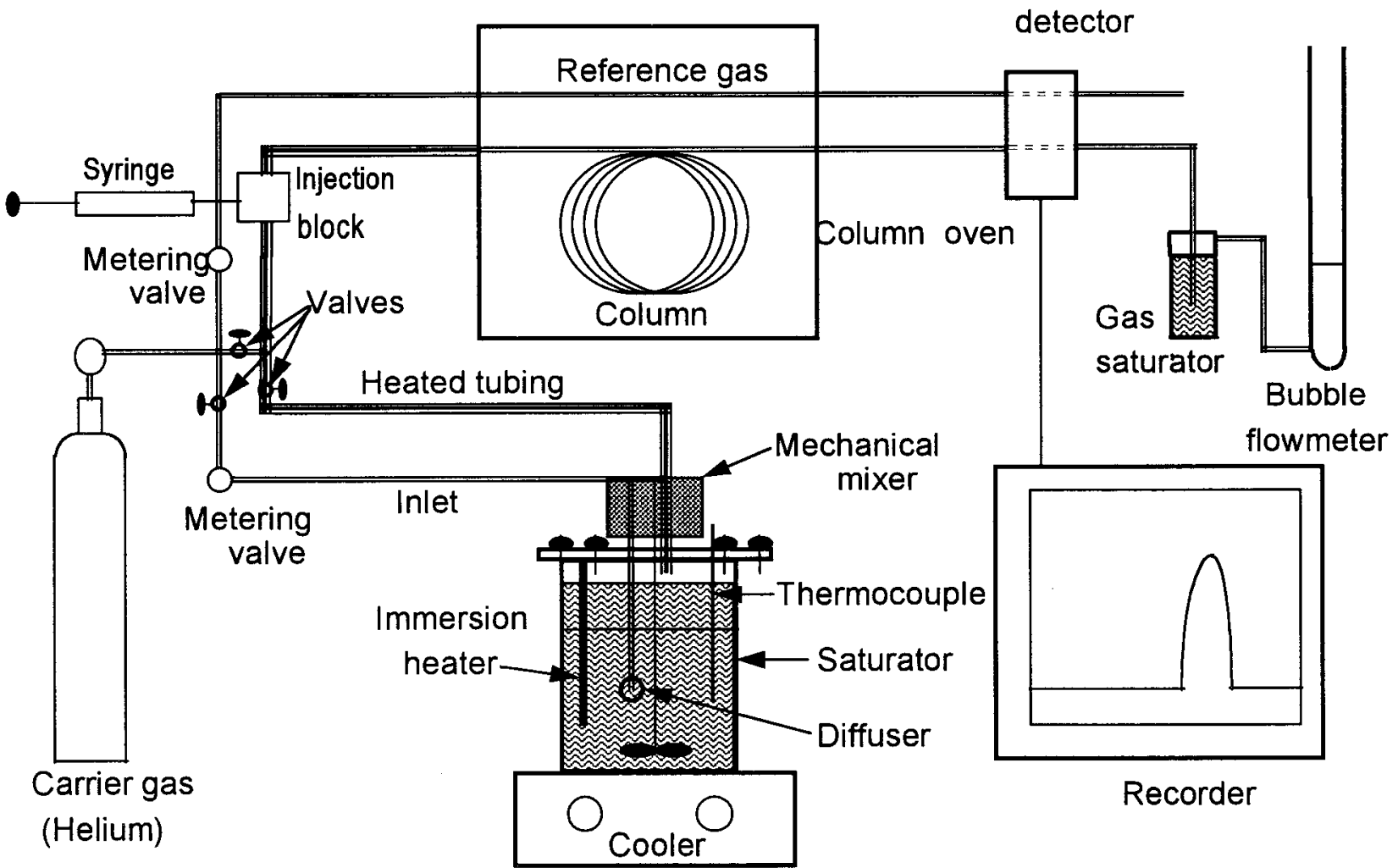

Figure 1. Schematic of the IGC apparatus.

solvents in amorphous polymers are based on free-volume concepts. These basic free-volume concepts were first proposed by Cohen and Turnbull, ${ }^{11}$ modified by Fujita ${ }^{12}$ for diffusion in amorphous, rubbery polymers, and refined by Vrentas and Duda ${ }^{13,14}$ for both self- and mutual diffusion in polymer-solvent systems. In this work, the Vrentas-Duda free-volume theory was used to correlate diffusion coefficients for polymer-solvent systems. The difference between the Fujita and Vrentas-Duda theories is the focus on the free volume per unit volume of solution by Fujita and the average free volume per jumping unit by Vrentas and Duda. Vrentas and Duda derived the following expression for the concentration and temperature dependence of the solvent self-diffusion coefficient in a polymer solution above the glass-transition temperature $\left(T_{g}\right)$ of the polymer, $D_{1}$ :

$$
D_{1}=D_{01} \exp \left[-\frac{\gamma\left(\omega_{1} \hat{V}_{1}^{*}+\omega_{2} \hat{V}_{2}^{*} \xi\right)}{\hat{V}_{F H}}\right]
$$

Here, $D_{o 1}$ is a constant pre-exponential factor, $\hat{\mathrm{V}}_{\mathrm{i}}^{*}$ is the specific critical hole free volume required for a diffusive jump of the component $i, R$ is the universal gas constant, $T$ is the absolute temperature, $\gamma$ is an overlap factor, and $\omega_{i}$ is the weight fraction of component $i$. The quantity $\xi$ is defined as the ratio of the critical volume of the solvent per mole to that of the polymer.

$$
\xi=\frac{M_{j_{1}} \hat{V}_{1}^{*}}{M_{j_{2}} \hat{V}_{2}^{*}}
$$

Here, $M_{j i}$ is the molecular weight of a jumping unit of component $i$. In eq $5, \hat{V}_{F H}$ is the specific hole free volume of the polymer-solvent mixture given by

$$
\begin{aligned}
\hat{V}_{F H}=\omega_{1} K_{11}\left(K_{21}-T_{g_{1}}\right. & +T) \\
& +\omega_{2} K_{12}\left(K_{22}-T_{g_{2}}+T\right)
\end{aligned}
$$

where $K_{1 i}$ and $K_{2 i}$ are free-volume parameters and $T_{g i}$ is the glass-transition temperature of component $i$. The free-volume parameters of the pure polymer and solvent can be obtained independently. Equation 5 can be used to regress experimental data for $D_{o 1}$ and $\xi$. The free-volume 


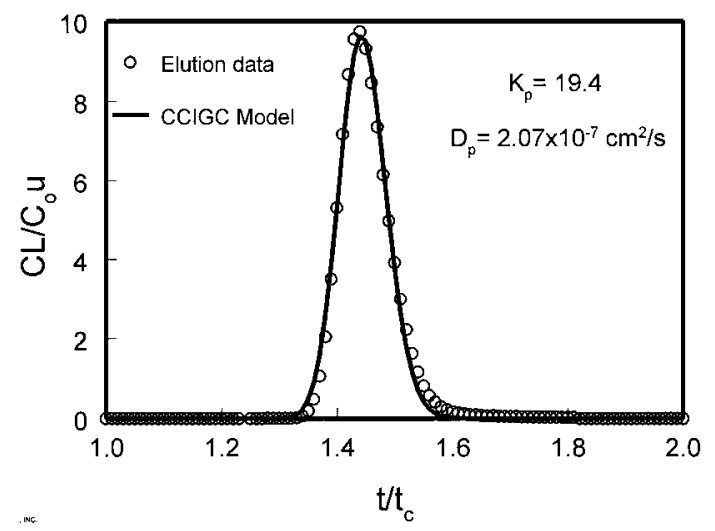

Figure 2. Comparison of the experimental elution profile and CCIGC model for the PS-toluene system at $180^{\circ} \mathrm{C}$.

equation can then be used to interpolate and extrapolate over wide ranges of temperatures and concentrations.

The self-diffusion coefficient of the solvent at zero concentration in a glassy polymer can be described as

$$
D_{1}=D_{01} \exp \left[-\frac{\gamma \hat{V}_{2}^{*} \xi}{K_{12}\left(K_{22}+\lambda\left(T-T_{g 2}\right)\right)}\right]
$$

The parameter $\lambda$ represents the volume contraction that can be attributed to the glass transition. Clearly, the actual value of $\lambda$ for the polymer will depend on the mechanical and thermal history of the material. The evaluation of the parameter $\lambda$ is usually done first through regression for $D_{o 1}$ and $\xi$ with data above the $T_{g}$. Equation 8 is then used to determine $\lambda$.

If the Flory-Huggins theory is invoked to describe the thermodynamic behavior of the system, the mutual diffusion coefficient, $D$, can be related

Table I. Partition and Diffusion Coefficients for the PS-Toluene System at Infinite Dilution

\begin{tabular}{ccc}
\hline$T\left({ }^{\circ} \mathrm{C}\right)$ & $K_{p}$ & $D_{p}\left(\mathrm{~cm}^{2} / \mathrm{s}\right)$ \\
\hline 110 & 70.9 & $8.50 \times 10^{-10}$ \\
120 & 62.4 & $2.17 \times 10^{-9}$ \\
130 & 44.5 & $4.73 \times 10^{-9}$ \\
140 & 39.0 & $1.73 \times 10^{-8}$ \\
150 & 31.4 & $3.30 \times 10^{-8}$ \\
160 & 27.3 & $6.43 \times 10^{-8}$ \\
180 & 19.4 & $2.10 \times 10^{-7}$ \\
\hline
\end{tabular}

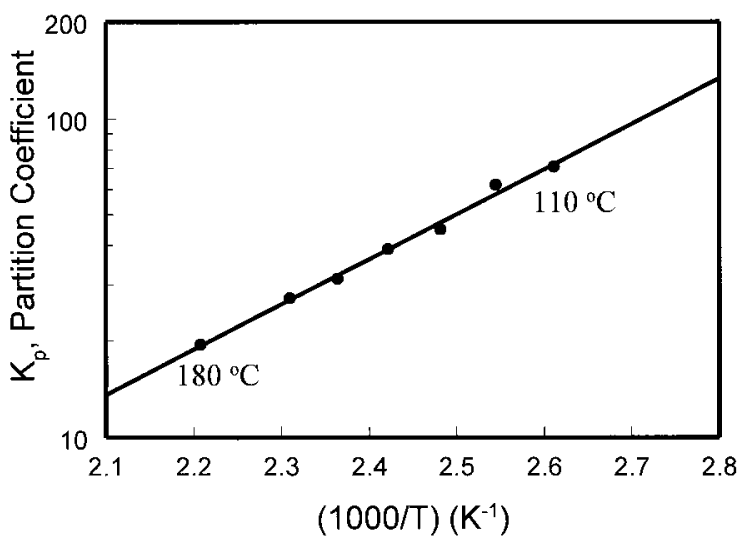

Figure 3. Temperature dependence of $K_{p}$ for the PStoluene system.

to the self-diffusion coefficient of the solvent, $D_{1}$, by the following relationship:

$$
D=D_{1}\left(1-\phi_{1}\right)^{2}\left(1-2 \chi_{12} \phi_{1}\right)
$$

Here, $\phi_{1}$ is the volume fraction of the solvent, and $\chi_{12}$ is the Flory-Huggins interaction parameter.

\section{EXPERIMENTAL}

The capillary column was prepared by Supelco Inc. (Bellefonte, PA). The column was $15 \mathrm{~m}$ long with a $0.53-\mathrm{mm}$ inner diameter. The thickness of the polymer coating was $3.0 \mu \mathrm{m}$. The solvents used were all reagent grade (99.8\% purity) as supplied by Aldrich Chemicals and were injected as liquids. PS was obtained from Pressure Chem Co. It had a molecular weight of approximately 15,000 and a $T_{g}$ of approximately $100{ }^{\circ} \mathrm{C}$.

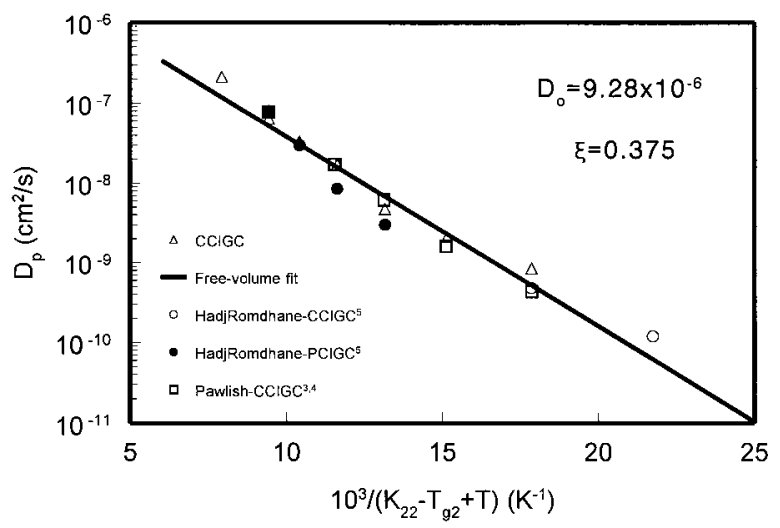

Figure 4. Infinite dilution diffusion coefficients for the PS-toluene system with free-volume correlation. 
Table II. Free-Volume Parameters of the PS-Toluene System ${ }^{a}$

$$
\begin{array}{lc}
\hat{V}_{1}^{*}\left(\mathrm{~cm}^{3} / \mathrm{g}\right) & 0.917 \\
\hat{V}_{2}^{*}\left(\mathrm{~cm}^{3} / \mathrm{g}\right) & 0.850 \\
K_{11} / \gamma\left(\mathrm{cm}^{3} / \mathrm{g} \mathrm{K}\right) & 2.21 \times 10^{-3} \\
K_{12} / \gamma\left(\mathrm{cm}^{3} / \mathrm{g} \mathrm{K}\right) & 5.82 \times 10^{-4} \\
K_{21}-T_{g 1}(\mathrm{~K}) & -103 \\
K_{22}-T_{g 2}(\mathrm{~K}) & -327 \\
\chi & 0.4
\end{array}
$$

${ }^{\text {a }}$ Parameter taken from Duda et al. ${ }^{19}$

Figure 1 is a schematic of the experimental apparatus. The apparatus is a modified form of that used by Price and Guillet. ${ }^{10}$ A Varian gas chromatogram (model 3400) equipped with a thermal conductivity detector, a flame ionization detector, a column injector, and a circulating air oven was used. For the infinite dilute solvent case, the carrier gas (helium) is fed directly to the capillary column, and a small amount of solvent is injected.

For finite concentration IGC, a uniform background concentration of the solvent is established in the carrier gas. The carrier gas is diverted to the saturator and then passes through a diffuser in the well stirred, temperature-controlled liquid bath. It leaves the saturator with its equilibrium vapor pressure in the carrier gas. Precise control of the temperature bath is needed to obtain a constant plateau concentration. Upon leaving the saturator, the gas flows through heated tubing to the injector block and then to the column. As in the infinite dilute case, a small pulse of the solvent is then injected. This technique is known as elution on a plateau. Through modeling of the response peak as described previously, the partition and diffusion coefficients are determined. An error analysis taking into account the length of the column, velocity of the gas, thickness of the coating, diameter of the capillary, and diffusion coefficient of the solvent in the gas phase showed that the errors in the partition coefficient and diffusion coefficient values are less than $10 \%$. Each experimental point reported in this article is the average of three experimental measurements.

\section{RESULTS AND DISCUSSION}

\section{Infinitely Dilute Region}

Infinite dilution experiments were performed for three polymer-solvent systems: PS-toluene, PSbenzene, and PS-hexane.

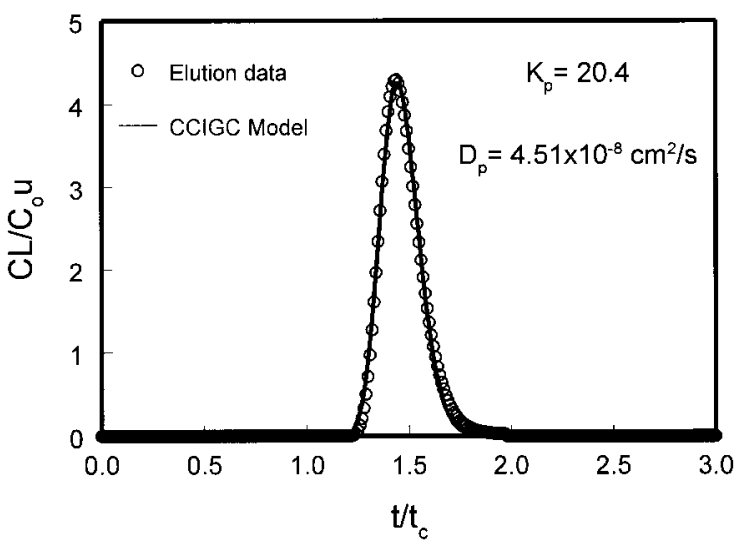

Figure 5. Comparison of the experimental elution profile and CCIGC model for the PS-benzene system at $150{ }^{\circ} \mathrm{C}$.

\section{PS-Toluene System}

The partition and diffusion measurements of toluene were performed in PS from 110 to $180{ }^{\circ} \mathrm{C}$, which is greater than the $T_{g}$ of the polymer $\left(T_{g}\right.$ $=100{ }^{\circ} \mathrm{C}$ ). Figure 2 shows the theoretical and experimental elution profiles of toluene in PS at $180{ }^{\circ} \mathrm{C}$. The points represent the experimental data, whereas the solid lines represent the theoretical elution curves obtained with regressed values of the partition, $K_{p}$, and diffusion coefficients, $D_{p}$. The good agreement between the experimental and theoretical elution profiles is evidence that the CCIGC model accurately describes the chromatographic process. The infinitely dilute partition and diffusion coefficients are tabulated in Table I. Figure 3 shows the temperature dependence of the partition coefficients. The partition coefficient increases as the temperature de-

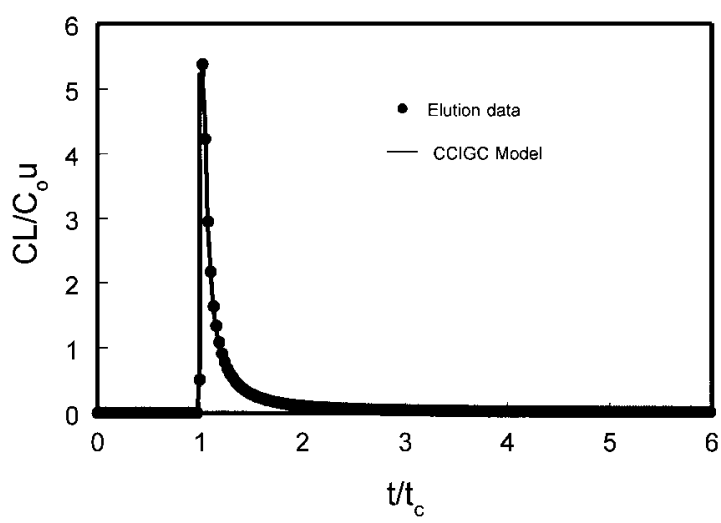

Figure 6. Comparison of the experimental elution profile and CCIGC model for the PS-benzene system at $90{ }^{\circ} \mathrm{C}$. 
Table III. Partition and Diffusion Coefficients of Benzene in PS at Infinite Dilution

\begin{tabular}{rcc}
\hline$T\left({ }^{\circ} \mathrm{C}\right)$ & $K_{p}$ & $D_{p}\left(\mathrm{~cm}^{2} / \mathrm{s}\right)$ \\
\hline 70 & 59.0 & $2.01 \times 10^{-11}$ \\
80 & 50.4 & $3.20 \times 10^{-11}$ \\
90 & 44.2 & $7.80 \times 10^{-11}$ \\
100 & 40.3 & $4.00 \times 10^{-10}$ \\
110 & 36.0 & $1.00 \times 10^{-9}$ \\
120 & 29.9 & $3.98 \times 10^{-9}$ \\
130 & 24.9 & $6.08 \times 10^{-9}$ \\
150 & 20.4 & $4.51 \times 10^{-8}$ \\
180 & 10.1 & $1.50 \times 10^{-7}$ \\
\hline
\end{tabular}

creases. This shows that the solvent solubility is inversely related to the temperature of the system. The functionality of $\log (K)$ with temperature is linear at temperatures greater than the glass transition of the polymer. With this relationship, partition coefficients can be predicted at higher temperatures. The change of the slope is expected because the heat of solution and, therefore, the $K$ value change at $T_{g}$ as reported by Laub and Pecsok. ${ }^{15}$

To analyze the temperature dependence of the diffusion coefficient of toluene in PS, the freevolume theory at infinite dilution of the solvent was used. Figure 4 shows the free-volume correlation of the diffusion data for the PS-toluene system. The diffusion coefficient data reported by Pawlisch et al., ${ }^{2,3}$ who used capillary columns, and HadjRomdhane, ${ }^{4}$ who used both packed columns (packed column inverse gas chromatography) and capillary columns (CCIGC), are also shown in Figure 4. There appears to be some

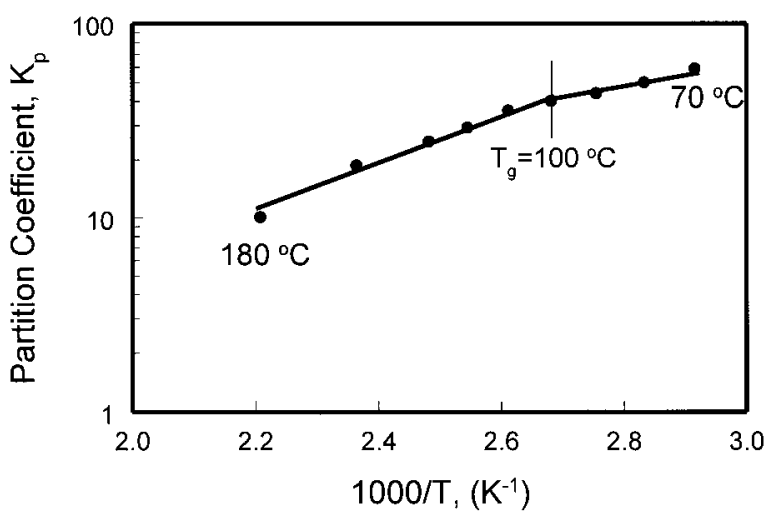

Figure 7. Partition coefficients as a function of temperature for the PS-benzene system at temperatures above and below the $T_{g}$ of the polymer.

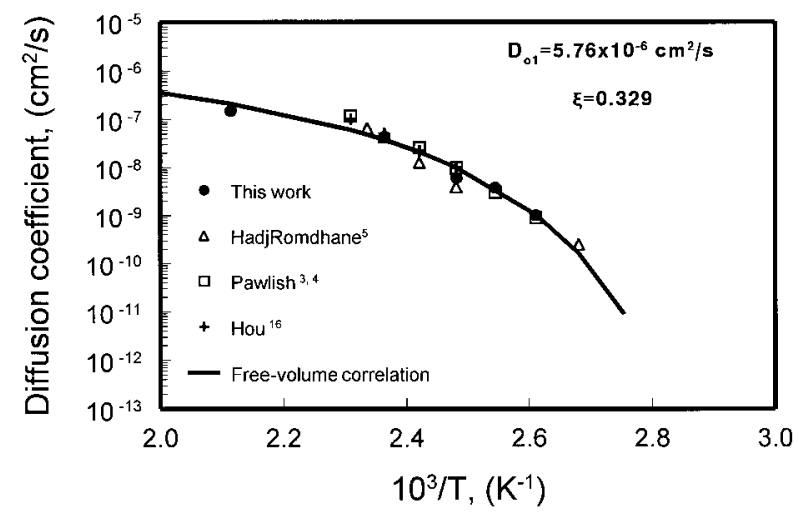

Figure 8. Diffusion data above the $T_{g}$ for the PSbenzene system.

discrepancy between the diffusion data obtained with packed columns and those obtained with capillary columns. The discrepancy is believed to be the result of the nonuniformity of the polymer film in the packed columns. All diffusion data in Figure 4 were correlated with free-volume theory. The correlation gives a value of $9.28 \times 10^{-6} \mathrm{~cm}^{2} / \mathrm{s}$ for $D_{o 1}$ and 0.375 for $\xi$. The free-volume parameters are presented in Table II.

\section{PS-Benzene System}

The PS-benzene system was studied at temperatures greater and less than the $T_{g}$ of the polymer. Figure 5 shows the elution profile at $150^{\circ} \mathrm{C}$. Because the temperature is far greater than the $T_{g}$, the elution profile is Gaussian. At $90^{\circ} \mathrm{C}$, however, the elution profile is skewed with a sharp front and a long tail. All elution profiles below the $T_{g}$ of PS were characterized by sharp fronts and tails, indicating slow solvent diffusion in the polymer. A typical example is shown in Figure 6 at 90 ${ }^{\circ} \mathrm{C}$. A summary of the values of $K_{p}$ and $D_{p}$ obtained above and below the $T_{g}$ for the PS-benzene system is given in Table III. Figure 7 shows the plot of the partition coefficient as a function of

Table IV. Free-Volume Parameters of the PS-Benzene System

\begin{tabular}{lc}
\hline$\hat{V}_{1}^{*}\left(\mathrm{~cm}^{3} / \mathrm{g}\right)^{\mathrm{a}}$ & 0.901 \\
$\hat{V}_{2}^{*}\left(\mathrm{~cm}^{3} / \mathrm{g}\right)^{\mathrm{a}}$ & 0.850 \\
$K_{11} / \gamma\left(\mathrm{cm}^{3} / \mathrm{g} \mathrm{K}\right)^{\mathrm{a}}$ & $1.07 \times 10^{-3}$ \\
$K_{12} / \gamma\left(\mathrm{cm}^{3} / \mathrm{g} \mathrm{K}\right)^{\mathrm{a}}$ & $5.82 \times 10^{-4}$ \\
$K_{21}-T_{g 1}(\mathrm{~K})^{\mathrm{a}}$ & -73.79 \\
$\xi$ & 0.329 \\
\hline
\end{tabular}

${ }^{\text {a }}$ Parameter taken from Zielinski and Duda. ${ }^{20}$ 


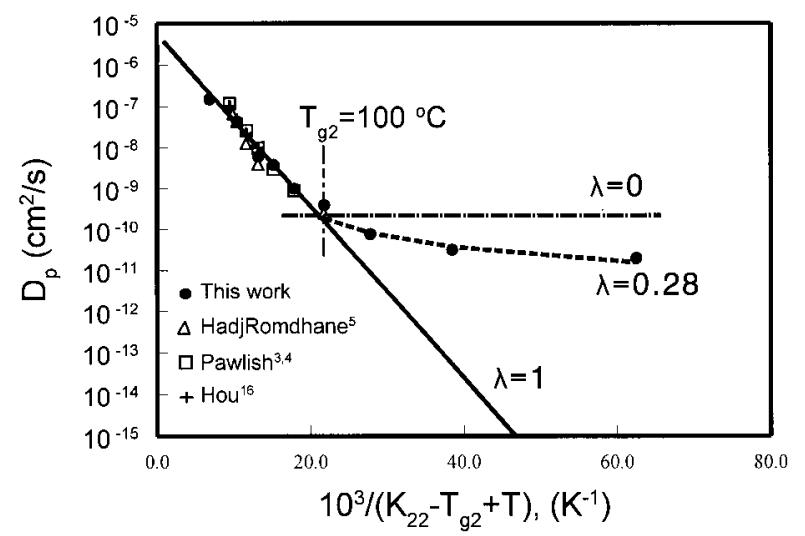

Figure 9. Diffusion data of benzene in PS above and below the $T_{g}$ of the polymer.

temperature. As before, the slope of the plot changes at the $T_{g}{ }^{15}$ Because the solvent is at infinite dilution, the $T_{g}$ remains at $100{ }^{\circ} \mathrm{C}$.

The correlative capabilities of the VrentasDuda free-volume theory above and below $T_{g}$ were tested. A regression for $D_{o 1}$ and $\xi$ was done according to eq 5 . Figure 8 reports the diffusion data above $T_{g 2}$ for the PS-benzene system. In this figure, the results of other investigators obtained with packed columns ${ }^{4,16}$ or capillary columns $^{2-4}$ are also shown. The regression of these data yielded a value of $5.76 \times 10^{-6} \mathrm{~cm}^{2} / \mathrm{s}$ for $D_{o 1}$ and 0.329 for $\xi$ (Fig. 8). The free-volume parameters used in the evaluation of the theory are given in Table IV.

The Vrentas-Duda free-volume theory, as applied to glassy polymers, was used to describe the diffusion of benzene below the glass transition of PS. The parameter $\lambda$ was regressed according to eq 8 , with the $D_{o 1}$ and $\xi$ values determined above the $T_{g}$. Figure 9 shows the diffusion above and below the $T_{g}$. A break occurs at $T_{g 2}$, and a $\lambda$ value

Table V. Partition and Diffusion Coefficients of Hexane in PS at Infinite Dilution

\begin{tabular}{lrc}
\hline$T\left({ }^{\circ} \mathrm{C}\right)$ & $K_{p}$ & $D_{p}\left(\mathrm{~cm}^{2} / \mathrm{s}\right)$ \\
\hline 110 & 10.2 & $7.50 \times 10^{-9}$ \\
110 & 11.0 & $8.40 \times 10^{-9}$ \\
130 & 8.6 & $9.35 \times 10^{-9}$ \\
130 & 9.0 & $1.04 \times 10^{-8}$ \\
150 & 7.4 & $2.27 \times 10^{-8}$ \\
150 & 7.9 & $2.47 \times 10^{-8}$ \\
180 & 4.5 & $4.37 \times 10^{-8}$ \\
180 & 5.2 & $5.09 \times 10^{-8}$ \\
\hline
\end{tabular}

Table VI. Free-Volume Parameters of the PS-Hexane System

\begin{tabular}{lc}
\hline$\hat{V}_{1}^{*}\left(\mathrm{~cm}^{3} / \mathrm{g}\right)^{\mathrm{a}}$ & 1.133 \\
$\hat{V}_{2}^{*}\left(\mathrm{~cm}^{3} / \mathrm{g}\right)^{\mathrm{a}}$ & 0.850 \\
$K_{11} / \gamma\left(\mathrm{cm}^{3} / \mathrm{g} \mathrm{K}\right)^{\mathrm{a}}$ & $1.96 \times 10^{-3}$ \\
$K_{12} / \gamma\left(\mathrm{cm}^{3} / \mathrm{g} \mathrm{K}\right)^{\mathrm{a}}$ & $5.82 \times 10^{-4}$ \\
$K_{21}-T_{g 1}(\mathrm{~K})^{\mathrm{a}}$ & -41.08 \\
$K_{22}-T_{g 2}(\mathrm{~K})^{\mathrm{a}}$ & -327 \\
$D_{01}\left(\mathrm{~cm}^{2} / \mathrm{s}\right)$ & $1.56 \times 10^{-7}$ \\
$\xi$ & 0.124 \\
\hline
\end{tabular}

${ }^{\text {a }}$ Parameter taken from Hong. ${ }^{21}$

of 0.28 correlates the PS-benzene diffusion data below $T_{g 2}$. For $\lambda=1$ (the extension of the correlation line above $T_{g 2}$ to temperatures less than $T_{g 2}$ ), the polymer would have its equilibrium liquid structure at all temperatures. If $\lambda$ is equal to 0 , the diffusion coefficients below the $T_{g}$ are not dependent on temperature. Values of $\lambda$ have also been determined by other researchers for PSsolvent systems: 0.25 for toluene, 0.30 for heptane and methyl ethyl ketone, ${ }^{4}$ and 0.31 for pentane. ${ }^{5}$ The good agreement obtained for $\lambda$ from five different solvents shows that in general this parameter is independent of the solvent. This behavior below the glass, of course, should depend on the annealing history of the polymer. If the temperature is lowered quite slowly under controlled conditions, a different polymer configuration may be obtained, and the diffusion coefficients (and $\lambda$ ) may change.

\section{PS-Hexane System}

Thermodynamic and diffusion data were collected for the PS-hexane system above the $T_{g}$ of the

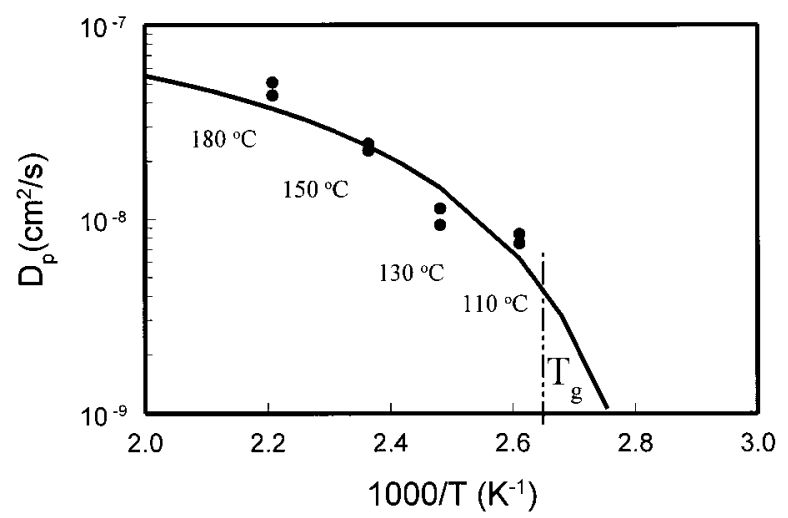

Figure 10. Free-volume correlation of the PS-hexane diffusion data. 


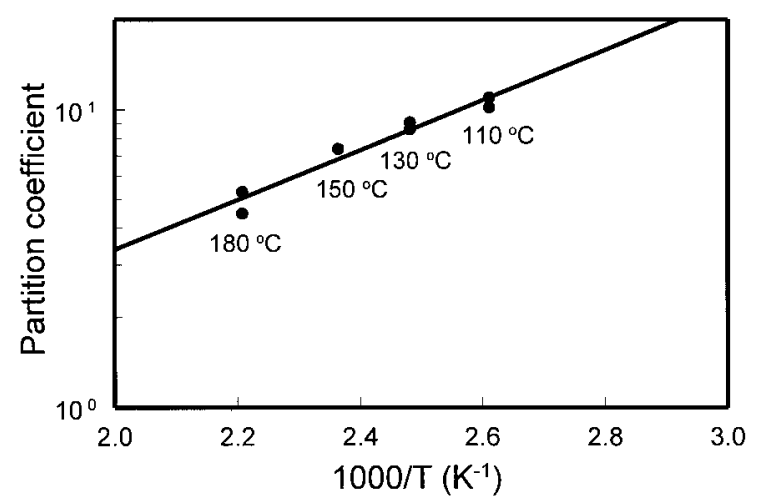

Figure 11. Temperature dependency of the solubility data for the PS-hexane system.

polymer. A similar analysis in terms of free-volume theory was made with the diffusivity data reported for the PS-hexane system in Table V. Table VI lists the parameters used in the correlation. Figure 10 shows the resulting free-volume correlation. The regressed parameters $\left(D_{o 1}\right.$ and $\left.\xi\right)$ determined for this system were $1.56 \times 10^{-7}$ $\mathrm{cm}^{2} / \mathrm{s}$ and 0.124 , respectively. No independent data were available for comparison.

Figure 11 illustrates the temperature dependency of the solubility data between 110 and 180 ${ }^{\circ} \mathrm{C}$. This linear relationship can be used to predict the solubility at higher temperatures.

\section{Finite Concentration Experiments}

The PS-toluene system was studied at finite concentrations up to about $11 \mathrm{wt} \%$ in the polymer from 110 to $180{ }^{\circ} \mathrm{C}$. A typical elution profile is shown in Figure 12 at $140{ }^{\circ} \mathrm{C}$ and a solvent weight

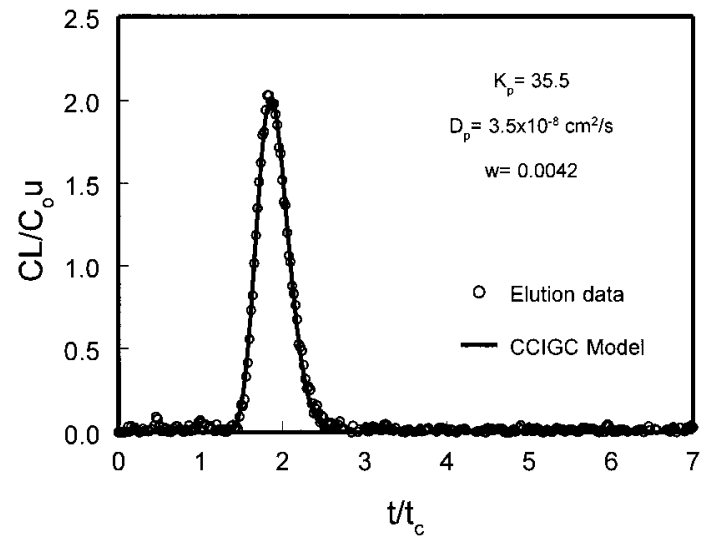

Figure 12. Elution profile for the PS-toluene system at $140{ }^{\circ} \mathrm{C}$ and a solvent weight fraction of 0.0042 .

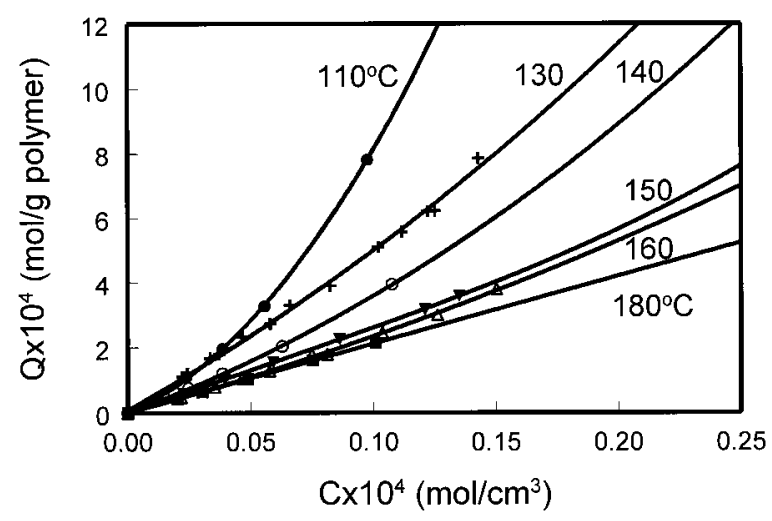

Figure 13. Absorption isotherms for the PS-toluene system.

fraction of 0.042 . The scatter in the elution data is significantly greater than in the infinitely dilute case as a result of slight variations in the saturator flow and temperature. Nevertheless, the model reproduces the experimental curve quite well.

Figure 13 illustrates the experimental absorption isotherms for the PS-toluene system at six different temperatures. As expected, the concentration of solvent in the polymer increases with the solvent concentration in the gas phase, and the slope of the isotherm becomes greater at lower temperatures. Figure 14 shows a comparison of the partition coefficients obtained from the retention volume theory expression, eq 4 (open circles), and from the finite concentration IGC model (solid circles) as a function of solvent concentration in the gas phase at two different temperatures. This figure also compares IGC data with gravimetric sorption data ${ }^{17,18}$ (open triangles). The lines rep-

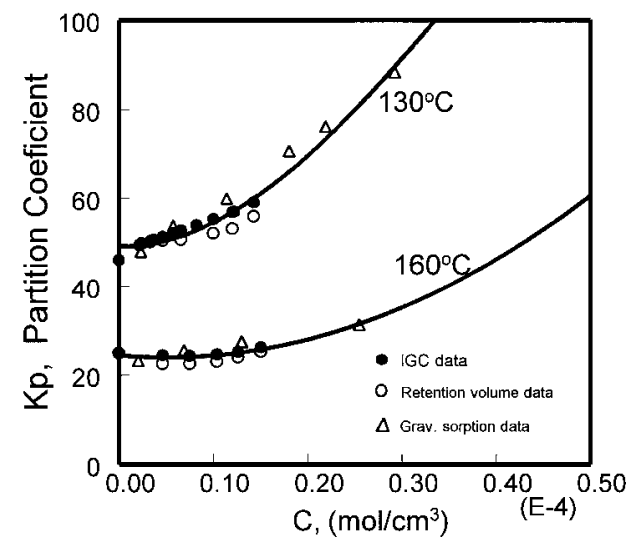

Figure 14. Partition coefficients as a function of solvent concentration in the gas phase. 
resent the best polynomial fit to all data. Partition coefficient data obtained by IGC are in good agreement with the values obtained from retention volume theory and sorption experiments.

Comparisons of the diffusivities obtained by the IGC and sorption methods along with the free-volume correlation for the PS-toluene system are shown in Figure 15 at 130 and $180{ }^{\circ} \mathrm{C}$. The regressed parameters $\left(D_{o 1}\right.$ and $\left.\xi\right)$ determined for this system were $1.04 \times 10^{-4} \mathrm{~cm}^{2} / \mathrm{s}$ and 0.503 , respectively. The data are in good agreement with the sorption data and are well correlated with the Vrentas-Duda free-volume theory. The experimental data are given in Table VII.

\section{CONCLUSION}

The CCIGC technique has been demonstrated to be a good method for measuring partition and diffusion coefficients over a wide temperature range for both infinite and finite concentrations. The method has been applied to toluene, benzene, and hexane at infinite dilution in PS. The PStoluene system has also been studied in the finite concentration region at various temperatures and concentrations. The Vrentas-Duda free-volume theory above and below the glass transition region is able to correlate the data in both the infinite and finite concentration regions. Partition coefficient data obtained by IGC are in good agreement with the values obtained from the retention volume theory approach. This study shows that the IGC technique can be effectively used to make both infinite and finite concentration measurements for diffusion coefficient measurements, thus increasing its applicability.

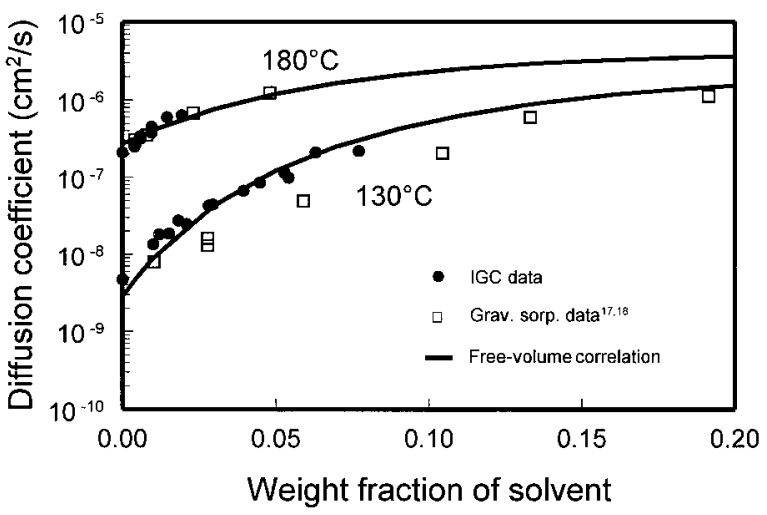

Figure 15. Finite concentration diffusivity data for the PS-toluene system.
Table VII. Experimental Data for the PS-Toluene System

\begin{tabular}{|c|c|c|c|}
\hline$T_{\text {column }}\left({ }^{\circ} \mathrm{C}\right)$ & $\omega_{1}$ & $K_{p}$ & $D_{p}\left(\mathrm{~cm}^{2} / \mathrm{s}\right)$ \\
\hline 110 & 0 & 70.0 & $8.50 \times 10^{-10}$ \\
\hline 110 & 0.0105 & 71.7 & $4.02 \times 10^{-9}$ \\
\hline 110 & 0.0177 & 74.1 & $9.77 \times 10^{-9}$ \\
\hline 110 & 0.029 & 77.3 & $1.93 \times 10^{-8}$ \\
\hline 110 & 0.045 & 82.8 & $6.41 \times 10^{-8}$ \\
\hline 110 & 0.067 & 87.9 & $1.59 \times 10^{-7}$ \\
\hline 130 & 0 & 46.0 & $4.73 \times 10^{-9}$ \\
\hline 130 & 0.0105 & 49.6 & $1.35 \times 10^{-8}$ \\
\hline 130 & 0.0112 & 50.4 & $1.80 \times 10^{-8}$ \\
\hline 130 & 0.0151 & 50.6 & $1.86 \times 10^{-8}$ \\
\hline 130 & 0.0182 & 51.3 & $2.78 \times 10^{-8}$ \\
\hline 130 & 0.0208 & 52.1 & $2.48 \times 10^{-8}$ \\
\hline 130 & 0.0281 & 52.7 & $4.30 \times 10^{-8}$ \\
\hline 130 & 0.0295 & 54.0 & $4.46 \times 10^{-8}$ \\
\hline 130 & 0.0395 & 55.3 & $6.70 \times 10^{-8}$ \\
\hline 130 & 0.0449 & 56.8 & $8.57 \times 10^{-8}$ \\
\hline 130 & 0.0528 & 57.0 & $1.15 \times 10^{-7}$ \\
\hline 130 & 0.0541 & 59.1 & $9.86 \times 10^{-8}$ \\
\hline 140 & 0 & 35 & $2.20 \times 10^{-8}$ \\
\hline 140 & 0.0042 & 35.5 & $3.50 \times 10^{-8}$ \\
\hline 140 & 0.0109 & 35.8 & $4.86 \times 10^{-8}$ \\
\hline 140 & 0.0185 & 36.6 & $6.23 \times 10^{-8}$ \\
\hline 140 & 0.035 & 39.2 & $1.06 \times 10^{-7}$ \\
\hline 150 & 0 & 31 & $3.30 \times 10^{-8}$ \\
\hline 150 & 0.0054 & 31.8 & $4.18 \times 10^{-8}$ \\
\hline 150 & 0.0094 & 32.7 & $4.92 \times 10^{-8}$ \\
\hline 150 & 0.014 & 33.6 & $5.87 \times 10^{-8}$ \\
\hline 150 & 0.0203 & 34.6 & $8.67 \times 10^{-8}$ \\
\hline 160 & 0 & 25.0 & $3.83 \times 10^{-7}$ \\
\hline 160 & 0.01 & 24.5 & $1.34 \times 10^{-7}$ \\
\hline 160 & 0.016 & 24.3 & $1.83 \times 10^{-7}$ \\
\hline 160 & 0.022 & 24.7 & $2.40 \times 10^{-7}$ \\
\hline 160 & 0.027 & 25.3 & $3.17 \times 10^{-7}$ \\
\hline 160 & 0.033 & 26.3 & $3.83 \times 10^{-7}$ \\
\hline 180 & 0 & 19.0 & $2.10 \times 10^{-7}$ \\
\hline 180 & 0.0039 & 20.2 & $2.80 \times 10^{-7}$ \\
\hline 180 & 0.0058 & 20.8 & $3.30 \times 10^{-7}$ \\
\hline 180 & 0.0095 & 22.0 & $4.30 \times 10^{-7}$ \\
\hline 180 & 0.0150 & 23.8 & $6.00 \times 10^{-7}$ \\
\hline 180 & 0.0193 & 25.2 & $6.40 \times 10^{-7}$ \\
\hline
\end{tabular}

\section{NOMENCLATURE}

$C$ solute concentration in the gas phase (mol/ $\mathrm{cm}^{3}$ )

$C^{\prime}$ solute concentration in the polymer phase $\left(\mathrm{mol} / \mathrm{cm}^{3}\right)$

$C_{0} \quad$ strength of the inlet impulse $\left(\mathrm{mol} \cdot \mathrm{s} / \mathrm{cm}^{3}\right)$

$D$ mutual diffusion coefficient $\left(\mathrm{cm}^{2} / \mathrm{s}\right)$

$D_{i} \quad$ solvent self-diffusion coefficient of component $i\left(\mathrm{~cm}^{2} / \mathrm{s}\right)$ 
$D_{o i} \quad$ pre-exponential constant of the diffusion coefficient of component $i\left(\mathrm{~cm}^{2} / \mathrm{s}\right)$

$D_{g} \quad$ solvent diffusion coefficient in the mobile phase $\left(\mathrm{cm}^{2} / \mathrm{s}\right)$

$D_{p} \quad$ solvent diffusion coefficient in the polymer phase $\left(\mathrm{cm}^{2} / \mathrm{s}\right)$

$j \quad$ pressure-drop correction factor

$K \quad$ slope of sorption isotherm $\left(d C^{\prime} / d C\right)$

$K_{11}$ solvent free-volume parameter $\left(\mathrm{cm}^{3} / \mathrm{g} \cdot \mathrm{K}\right)$

$K_{21}$ solvent free-volume parameter (K)

$K_{12}$ polymer free-volume parameter $\left(\mathrm{cm}^{3} / \mathrm{g} \cdot \mathrm{K}\right)$

$K_{22}$ polymer free-volume parameter (K)

$K_{P}$ equilibrium partition coefficient $\left(C^{\prime} / C\right)$

$L \quad$ length of the column $(\mathrm{cm})$

$M_{2 j} \quad$ molecular weight of a polymer jumping unit ( $\mathrm{g} / \mathrm{mol}$ jumping unit)

$Q \quad$ solvent concentration in the polymer phase (mol/g polymer)

$\mathrm{R} \quad$ inner radius of the column $(\mathrm{cm})$

$R_{g} \quad$ gas constant $(\mathrm{J} / \mathrm{mol} \cdot \mathrm{K})$

$S$ Laplace operator

$t$ time (s)

$t_{c} \quad$ residence time of the carrier gas $(\mathrm{s})$

$T$ temperature (K)

$T_{g i}$ glass-transition temperature of component $i$ (K)

$u \quad$ mean velocity of the carrier gas $(\mathrm{cm} / \mathrm{s})$

$\hat{V}_{i}^{*} \quad$ specific critical hole free-volume of component $i\left(\mathrm{~cm}^{3} / \mathrm{g}\right)$

$V_{N} \quad$ net retention volume $\left(\mathrm{cm}^{3}\right)$

$V_{s} \quad$ volume of the stationary liquid phase $\left(\mathrm{cm}^{3}\right)$

$W$ mass of the polymer (g)

$\alpha \quad$ dimensionless thermodynamic parameter

$\beta \quad$ dimensionless polymer-phase diffusion parameter

$\Gamma \quad$ dimensionless gas-phase diffusion parameter

$\xi \quad$ ratio of solvent and polymer jumping units

$\lambda$ parameter (represents the change of volume contraction)

$\tau \quad$ film thickness in the capillary column $(\mathrm{cm})$

$\phi_{i} \quad$ volume fraction of the component $i$

$\chi \quad$ Flory-Huggins polymer-solvent interaction parameter

$\Psi \quad$ pressure-corrected mole fraction of vapor in carrier gas

$\omega_{i} \quad$ weight fraction of component $i$

\section{REFERENCES AND NOTES}

1. Gray, D. G.; Guillet, J. E. Macromolecules 1973, 6, 223.

2. Pawlisch, C. A.; Bric, J. R.; Laurence, R. L. Macromolecules 1988, 21, 1685-1698.

3. Pawlisch, C. A.; Macris, A.; Laurence, R. L. Macromolecules 1987, 20, 1564-1578.

4. HadjRomdhane, I. Polymer-Solvent Diffusion and Equilibrium Parameters by Inverse Gas-Liquid Chromatography. Ph.D. Thesis, Pennsylvania State University, University Park, PA, 1994.

5. Surana, R. K.; Danner, R. P.; Tihminlioglu, F.; Duda, J. L. J Polym Sci Part B: Polym Phys 1997, $35,1233$.

6. Tihminlioglu, F.; Surana, R. K.; Danner, R. P.; Duda, J. L. J Polym Sci Part B: Polym Phys 1997, 35, 1279 .

7. Arnould, D. D.; Laurence, R. L. Solute Diffusion in Polymers by Capillary Column Inverse Gas Chromatography. In Inverse Gas Chromatography; Lloyd, D. R.; Ward, T. C.; Shreiber, H. P., Eds.; ACS Symposium Series 391; American Chemical Society: Washington, DC, 1989; pp 87-106.

8. Tihminlioglu, F.; Danner R. P. J Chromatogr A 1999, 845, 93-101.

9. Conder, J. R.; Young, C. L. Physicochemical Measurements by Gas Chromatography; Wiley: New York, 1979.

10. Price, G. J.; Guillet, J. E. J Macromol Sci Chem 1986, 23, 1487.

11. Cohen, M. H.; Turnbull, D. J Chem Phys 1959, 31, 1164.

12. Fujita, H. Fortschr Hochpolym-Forsch 1961, 3, 1.

13. Vrentas, J. S.; Duda, J. L. J Polym Sci 1977, 15, 403.

14. Vrentas, J. S.; Duda, J. L. J Polym Sci 1977, 15, 417.

15. Laub, R. J.; Pecsok, R. L. Physicochemical Applications of Gas Chromatography; Wiley: New York, 1978.

16. Hou, A.-C. Molecular Diffusion in Concentrated Polymer Solutions. Ph.D. Thesis, Pennsylvania State University, University Park, PA, 1986.

17. Sun, K. W. Diffusion of Toluene in Molten Polystyrene. M.S. Thesis, Pennsylvania State University, University Park, PA, 1974.

18. Ni, Y. M. Evaluation Free-Volume Theory for Molecular Diffusion in Polymer Solutions. Ph.D. Thesis, Pennsylvania State University, University Park, PA, 1978.

19. Duda, J. L.; Vrentas, J. S.; Ju, S. T.; Liu, H. T. AIChE J 1982, 28, 279.

20. Zielinski, J. M.; Duda, J. L. AIChE J 1992, 38, 405.

21. Hong, S.-U. Ind Eng Chem Research 1995, 34, 2536. 